\title{
Geraniol Ameliorates the Motor Behavior and Neurotrophic Factors Inadequacy in MPTP-Induced Mice Model of Parkinson's Disease
}

\author{
Karamkolly R. Rekha • Govindasamy P. Selvakumar • \\ Subramaniam Sethupathy • Karunanidhi Santha • \\ Ramu Inmozhi Sivakamasundari
}

Received: 16 June 2013 / Accepted: 11 July 2013 / Published online: 13 August 2013

(C) The Author(s) 2013. This article is published with open access at Springerlink.com

\begin{abstract}
Many experiments affirm the notion that augmentation of neurotrophic factors (NTFs) activity, especially brainderived neurotrophic factors and glial cell-derived neurotrophic factors, could prevent or halt the progress of neurodegeneration in Parkinson's disease (PD). In this study, we investigated the therapeutic accomplishment of geraniol (GE $100 \mathrm{mg} / \mathrm{kg}$ ) on 1methyl-4-phenyl-1, 2, 3, 6-tetrahydropyridine (MPTP)-induced mice model of PD. Current investigation proved that pretreatment with GE ameliorates the MPTP-induced alterations in behavioral, biochemical, immunohistochemical, and immunoblotting manifestations in mice. Systematically, the loss of dopaminergic neurons and reduced NTFs mRNA expressions induced by MPTP was ameliorated to a significant extent by pretreatment with GE. We found that GE confers a potent neuroprotective agent against MPTP-induced dopaminergic denervation and may become a potential therapeutic agent for $\mathrm{PD}$ and/or its progression.
\end{abstract}

Keywords Neurotrophic factors · Neurodegeneration ·

Parkinson's disease $\cdot$ Neuroprotective

\section{Abbreviations \\ NTFs Neurotrophic factors \\ BDNF Brain-derived neurotrophic factors}

K. R. Rekha $\cdot$ S. Sethupathy $\cdot$ K. Santha $\cdot$

R. I. Sivakamasundari $(\bowtie)$

Division of Biochemistry, Faculty of Medicine, Raja Muthaiah

Medical College, Annamalai University, 608002 Annamalainagar,

Tamil Nadu, India

e-mail: inmozhipdresearch@gmail.com

G. P. Selvakumar

Department of Biochemistry and Biotechnology, Faculty of science

Annamalai University, Annamalainagar, Tamil Nadu, India

$\begin{array}{ll}\text { GDNF } & \text { Glial cell-derived neurotrophic factors } \\ \text { PD } & \text { Parkinson's disease } \\ \text { GE } & \text { Geraniol } \\ \text { MPTP } & \text { 1-methyl-4-phenyl-1 2, 3, 6-tetrahydropyridine } \\ \text { SN } & \text { Substantia nigra } \\ \text { DA } & \text { Dopamine } \\ \text { ST } & \text { Striatum } \\ \text { MPP } & \text { 1-methyl-4-phenylpyridinium ion } \\ \text { DAT } & \text { Dopamine transporter } \\ \text { VMAT-2 } & \text { Vesicular monoamine transporter 2 } \\ \text { LPO } & \text { Lipid peroxidation } \\ \text { MDA } & \text { Malonaldehyde } \\ \text { GSH } & \text { Reduced glutathione } \\ \text { DMRT } & \text { Duncan's multiple range test } \\ \text { DOPAC } & \text { Dihydroxyphenylacetic acid } \\ \text { HVA } & \text { Homovanillic acid } \\ \text { GAPDH } & \text { Glyceraldehyde-3-phosphate dehydrogenase }\end{array}$

\section{Introduction}

Parkinson's disease (PD) is one of the most studied neurological diseases (Wu and Frucht 2005) characterized by a progressive degeneration of dopaminergic neurons in substantia nigra (SN) (Collier et al. 2011). The loss of SN neurons leads to dopamine (DA) depletion in the striatum (ST), which results in motor impairments. Nowadays, many animal models of PD are obtainable (Hirsch 2007) by 1-methyl-4-phenyl-1, 2, 3, 6-tetrahydropyrindine (MPTP) and 6-hydroxydopamine (Schober 2004; Schwarting and Huston 1996). The MPTP model constitutes the best characterized toxin paradigm for PD, faithfully replicating most of its clinical and pathological hallmarks (Eberhardt and Schulz 2003). Since it is a lipophilic molecule that crosses the blood-brain barrier and converted to 
1-methyl-4-phenylpyridinium ion $\left(\mathrm{MPP}^{+}\right)$, which is taken up by dopaminergic terminals and cell bodies by the dopamine transporter (DAT) (Smeyne and Jackson-Lewis 2005). It accumulates in mitochondria resulting in oxidative stress and cell loss (Nicholas 2007; Przedborski et al. 2004; Wu et al. 2002).

Microglia are the major resident immune cells in the brain providing innate immunity; however, astrocytes and oligodendrocytes are also involved in the neuroinflammatory response (Tansey et al. 2007). It maintains the homeostasis of the brain through the production of various NTFs. NTFs, such as brain-derived neurotrophic factor (BDNF), insulinlike growth factor 1, glial cell-derived neurotrophic factor (GDNF), and neurotrophin nerve growth factor that are important for the survival, maintenance, and regeneration of specific neuronal populations in the adult brain (Mogi et al. 1999).

The neuroprotective or neurorescue activities of these NTFs have been demonstrated in a number of in vitro and in vivo experiments (Peterson and Nutt 2008). The depletion of these neurotrophic factors has been linked with disease pathology and symptoms of PD. BDNF accelerate DA turnover in the ST and plays an important role in maintaining the normal function and regeneration of DA neurons in the adult brain (Lindsay et al. 1994). GDNF is a member of the transforming growth factor- $\beta$ super family of neurotrophic factor (Saarma 2000). It is required for the survival of dopaminergic neurons (Lin et al. 1993) and promotes recovery in rodent and nonhuman primate models of PD (Kordower et al. 2000; Dowd et al. 2005). GDNF levels are decreased in the SN of PD patients (Jenner and Olanow 1998) and in normal aged rodents (Yurek and Fletcher-Turner 2001), suggesting its involvement in motor dysfunction and DA neuron degeneration. It has been hypothesized that neurotrophic factors might have the ability to restore the function of dopaminergic neurons (Hong et al. 2008; Yang et al. 2009). However, these factors cannot reach their target areas in the brain by systematic administration. Therefore, an important new research field which involves the search for small molecules that can enter the brain tissue and then trigger the endogenous neuroprotective mechanisms (Xu et al. 2010) is the potential therapeutics for neurodegenerative diseases.

Geraniol (GE), an acyclic monoterpene alcohol found in lemongrass and aromatic herb oils, proved to have cytoprotective and antioxidant potential in oxidative stress-induced animal models (Tiwari and Kakkar 2009). It also modulates the activity of enzymatic and nonenzymatic antioxidants (Madankumar et al. 2013). The protective effect of this compound against oxidative stress will open new insights for their therapeutic use in inflammatory diseases and other diseases where oxidative stress is a crucial event. Consequently, in the present investigation, we demonstrate the neuroprotective effects of GE on MPTP-induced behavioral deficits, oxidative stress, and alter the expressions of NTFs, tyrosine hydroxylase (TH), DAT, and vesicular monoamine transporter 2 (VMAT2) in a mouse model of PD.

\section{Materials and Methods}

Animals

Ten-week-old male C57BL/6 mice (25-30 g) purchased from the National Institute of Nutrition, Hyderabad were used in the present study. The animals were group-housed two animals per cage in a 12:12 h light/dark cycle with free access to food pellets and water. All experimental procedures were conducted according to the National Guidelines on the Proper Care and Use of Animals in Laboratory Research (Indian National Science Academy, New Delhi, 2000) and were approved by the animal ethics committee of the institute (reg. no. 160/1999/ CPCSEA; approval no: 881/2012) RMMC.

\section{MPTP Challenge}

\section{Experimental Design and Dosage Fixation}

A pilot study was conducted with four different doses of GE (50, 100, and $200 \mathrm{mg} / \mathrm{kg}$ ) to determine the dose-dependent effect of GE in MPTP-induced PD mice. It was observed that after the experimental period of 7 days, GE oral pretreatment at the doses of 50,100 , and $200 \mathrm{mg} / \mathrm{kg}$ significantly improved the levels of dopamine and its metabolites in MPTPinduced mice. From the results, it was observed that 100 and $200 \mathrm{mg} / \mathrm{kg}$ of GE administration showed similar induction in dopamine levels but more significant than $100 \mathrm{mg} / \mathrm{kg}$. As per result, we have selected the optimum dose $(100 \mathrm{mg} / \mathrm{kg})$ for our acute study.

The mice were randomized and divided into 4 groups of 18 mice each. Six mice in each group were used for biochemical analysis, another six mice were used for catecholamine, and the remaining mice were used for molecular studies (immunohistochemical studies, mRNA expressions, and western blot analysis). We followed the safety guidelines for handling of MPTP as reported previously (Lau et al. 2005).

Group I mice were treated with saline served as control. Groups II and III mice received intraperitoneal injection of MPTP (30 mg/kg body weight (bw); Lin et al. 2004) for 4 days consecutively starting from 4 th to 7 th day of the experimental period. In addition, group III mice received GE $(100 \mathrm{mg} / \mathrm{kg}$ bw in absolute ethanol) orally ( $1 \mathrm{~h}$ prior to each MPTP injection) for 7 days consecutively, starting from 1st to 7th day of the experimental period. Group IV mice received GE $(100 \mathrm{mg} / \mathrm{kg})$ dissolved in absolute ethanol and administered for 7 days by oral gavage. At the end of the 
experiment (8th day), the following behavioral tests were performed.

\section{Behavioral Studies}

\section{Rotarod Performance}

The rotarod test, in which animals walk on a rotating rod, is widely used to assess motor status in laboratory rodents. Performance is measured by the duration that an animal stays upon the rod as a function of rod speed. Here, we report that the task provides a rich source of information. Mice were allowed to adjust their posture in order to maintain their balance on a rotating rod at speeds of 5, 10, 15, and $20 \mathrm{rpm}$. The average retention time on the rod was calculated as described previously (Rozas et al. 1998).

\section{Drag Test}

This test was performed to measure the ability of the animal to balance its body posture using forelimbs in response to an externally imposed dynamic stimulus (Viaro et al. 2008). Each mouse was gently lifted using the tail (allowing the forepaws on the table) and dragged backwards at a constant speed (about $20 \mathrm{~cm} / \mathrm{s}$ ) for a fixed distance $(120 \mathrm{~cm})$. The number of touches made by each forepaw was counted by two independent observers (mean between the two forepaws).

\section{Footprint Analysis}

The footprint analysis was performed as described previously (Tillerson et al. 2002) with slight modification. Briefly, the mice were trained to run toward an enclosed square box in an open-top runway. The forepaws and hind paws were dipped with nontoxic paints, and the mice were immediately placed on one end of the sheet of paper opposite to the square box. The footprint patterns were analyzed for stride length by calculating from the mid digit toe of the first step to the heel of the second step.

\section{Biochemical Studies}

\section{Lipid Peroxidation Assay: Malonaldehyde}

Malonaldehyde (MDA), the final products of lipid peroxidation (LPO), was measured by a colorimetric assay using the Bioxytech LPO-586 colorimetric kit assay (OxisResearch, Portland, OR, USA) (Escames et al. 1997). Briefly, ST tissue samples were homogenized in 20 volumes $(\mathrm{w} / \mathrm{v})$ of ice cold $20 \mathrm{mM}$ Tris $\mathrm{HCl}$ buffer, $\mathrm{pH}$ 7.4. The homogenates were centrifuged at $1000 \times \mathrm{g}$ for $10 \mathrm{~min}$ at $4{ }^{\circ} \mathrm{C}$. Aliquots of the supernatant was incubated at $45{ }^{\circ} \mathrm{C}$ for $40 \mathrm{~min}$ in the presence of $\mathrm{N}$-methyl-2-phenylindole/methanol and methanesulfonic acid. The reaction was stopped by chilling samples on ice and centrifuged at $12,000 \times g$ for $5 \mathrm{~min}$ at $4{ }^{\circ} \mathrm{C}$. The absorbance in the supernatant was estimated spectrophotometrically at $586 \mathrm{~nm}$, and concentrations were calculated from a standard curve made with known amounts of MDA.

Reduced Glutathione The level of reduced glutathione (GSH) in the brain homogenate was measured by the method described by Jollow et al. (1974). Brain tissue homogenate was centrifuged at $16,000 \times g$ for $15 \mathrm{~min}$ at $40{ }^{\circ} \mathrm{C}$. The supernatant $(0.5 \mathrm{ml})$ was added to $4 \mathrm{ml}$ of ice-cold $0.1 \mathrm{mM}$ solution of 5, 5-dithiobis[2-nitrobenzoic acid] in $1 \mathrm{M}$ phosphate buffer ( $\mathrm{pH} 8)$. The optical density was read at $412 \mathrm{~nm}$ in a spectrophotometer.

\section{Striatal Dopamine and Its Metabolites}

The levels of DA, dihydroxyphenylacetic acid (DOPAC) and homovanillic acid (HVA) were determined by HPLC apparatus with an electrochemical detector (Muralikrishnan and Mohanakumar 1998). Briefly, the striatum was sonicated in ice-cold $0.1 \mathrm{M} \mathrm{HClO} 4$ containing $0.01 \%$ EDTA. The supernatant collected after a spin of $10,000 \times \mathrm{g}$ for $5 \mathrm{~min}$ was injected $(10 \mathrm{ml})$ into the HPLC system. Results were expressed as nanogram per milligram wet weight of brain tissue.

\section{Immunohistochemistry}

For immunohistochemical analysis, mice were deeply anesthetized with ketamine immediately after the behavioral test and were intracardially perfused with saline, followed by $4 \%$ of the fixative solution (formaldehyde in $0.1 \mathrm{M}$ phosphate buffer, $\mathrm{pH}$ 7.4). The brain (SN) was sectioned coronally at $5 \mu \mathrm{m}$ thickness on a cryostat. Sections were collected in $0.01 \mathrm{M}$ phosphate-buffered saline (PBS) and processed. Sections were collected in 0.01 M PBS and processed free floating (Hartmann et al. 2001). The latter sections were incubated with $0.3 \%$ hydrogen peroxide for $10 \mathrm{~min}$ at room temperature to remove the endogenous peroxidase activity and then placed in blocking buffer containing $10 \%$ normal goat serum (NGS) with $0.2 \%$ Triton X-100 in $0.01 \mathrm{M}$ PBS (pH 7.2) for $30 \mathrm{~min}$ at $37^{\circ} \mathrm{C}$. In each treatment, the slides were washed at least three times with $0.01 \mathrm{M}$ PBS each for $5 \mathrm{~min}$. Sections were incubated for $24 \mathrm{~h}$ with primary anti-mouse $\mathrm{TH}$ $(1: 1,000)$ in $2 \%$ NGS, $0.2 \%$ Triton X-100, and $0.02 \%$ sodium azide in Tris-buffered saline (TBS). After washing with $1 \%$ NGS in TBS, the sections were incubated in anti-mouse IgG-HRP conjugated antibody $(1: 1,000)$ in $1.5 \% \mathrm{NGS}$ for $1 \mathrm{~h}$. TH immunoreactivity was visualized in 
SN after incubation in 3,4-diaminobenzidine for 2-5 min. Sections were mounted with DPX mounting medium and cover slip.

The intensity of TH immunoreactivity in the SN was quantified by optical density measurements using the MicroComputer Imaging Device software; data were presented as a percent of the control group values. The number of TH immunoreactive cells on each representative mesencephalic section was counted for the SN region by persons who were blind to the treatment. Cell counts were determined every sixth section (total $8-10$ sections) through SN corresponding to the bregma -2.92 to $-3.64 \mathrm{~mm}$ from each of the animals, and three animals/group were used for cell counts. All raw cell counts were adjusted with a correction formula for cell size and section thickness according to the method of Abercrombie (1946). When counting was complete, the slides were decoded and arranged based on treatment group. The cell counts were then averaged for each animal, and these averages were used to calculate a mean $\pm \mathrm{SD}$ for each treatment group, and data were presented as a percent of the control group.

\section{Extraction of Total mRNA}

After the $24 \mathrm{~h}$ last GE administration, the mice were sacrificed, the brains were removed immediately, and the ST was dissected on ice and immediately transferred to dry ice to preserve mRNA integrity. These regions were used to analyze the dopaminergic nigrostriatal pathway affected by MPTPinduced neurodegeneration. Total mRNA was isolated from the ST using mRNA extraction kit (Genei Bangalore, India), following the manufacturer's instructions. The mRNA integrity was determined by agarose gel electrophoresis, and the concentration and purity were measured spectrophotometrically (Kingston et al. 1996).

Total mRNA was converted to single stranded cDNA using $2 \mu \mathrm{g}$ of total mRNA as a template. Oligo(dT) 12-18 primer (Invitrogen Life Technologies) and Moloney murine leukemia virus reverse transcriptase (RT; Invitrogen Life Technologies) were used as per manufacture's instruction. The following primers were used for the mRNA expression: BDNF: (Gene ID NM_007540.4) forward primer: 5'-ATCCAAATATGG CACAGCAA-3' reverse primer: 5'-TTCTGCCTGAGTT TTGATGC-3'; GDNF: (Gene ID NM_010275.2) forward primer: 5'-AAGGTCACCAGATAAACAAGCGG-3' reverse primer: 5'-TCACAGGAGCCGCTGCAATATC-3'; $\beta$-actin: forward primer 5'-AGC CAT GTA CGT AGC CAT CC-3' reverse primer 5'-CTC TCA GCT GTG GTG GTG AA-3'; GAPDH: forward primer 5'-GACCACAGTCCATGC CATCAC-3' reverse primer 5'-GCTGTTGAAGTCGCAG GAGAC-3'.

\section{Real Time-PCR}

The specific mRNA expressions were performed by real-time PCR, by subjecting the resulting cDNA to PCR amplification using 96-well optical reaction plates in the Eppendorf (Thermocycler) real-time PCR instrument, software version V1.5.0.39 (Genei Bangalore, India). Twenty-five microliter of reaction mixture contained $0.1 \mu \mathrm{l}$ of $10 \mu \mathrm{M}$ forward primer and $0.1 \mu \mathrm{l}$ of $10 \mu \mathrm{M}$ reverse primer $(40 \mathrm{nM}$ final concentration of each primer), $12.5 \mu \mathrm{l}$ of Red Eye RT Mastermix, $11.05 \mu \mathrm{l}$ of nuclease-free water, and $1.25 \mu \mathrm{l}$ of cDNA sample. The primers used in the current study were chosen from previously published studies and are listed above. Assay controls were incorporated on to the same plate, namely, no template controls to test for the contamination of any assay reagents. After sealing the plate with an optical adhesive cover, the thermocycling conditions were initiated at $95{ }^{\circ} \mathrm{C}$ for $10 \mathrm{~min}$, followed by 40 PCR cycles of denaturation at $95{ }^{\circ} \mathrm{C}$ for $15 \mathrm{~s}$, and anneal/ extension at $60^{\circ} \mathrm{C}$ for $1 \mathrm{~min}$. Melting (dissociation stage) was performed by the end of each cycle to ascertain the specificity of the primers and the purity of the final PCR product.

\section{Western Blotting}

Striatal synaptosomes were prepared according to the methods described by Wright et al. (1998). In brief, ST tissue was homogenized in an ice-cold RIPA buffer (1\% Triton, $0.1 \% \mathrm{SDS}, 0.5 \%$ deoxycholate, $1 \mathrm{mmol} / \mathrm{L}$ EDTA, $20 \mathrm{mmol} /$ $\mathrm{L}$ Tris (pH 7.4), $150 \mathrm{mmol} / \mathrm{L} \mathrm{NaCl}, 10 \mathrm{mmol} / \mathrm{L} \mathrm{NaF}$, and $0.1 \mathrm{mmol} / \mathrm{L}$ phenyl-methyl sulfonyl fluoride). The homogenate was centrifuged at $12,000 \mathrm{rpm} / \mathrm{min}$ for $15 \mathrm{~min}$ at $4{ }^{\circ} \mathrm{C}$ to remove debris. Protein concentration was measured by the method of Lowry et al. (1951). Samples containing $40 \mu \mathrm{g}$ of total cellular proteins were loaded and separated on $10 \%$ SDS polyacrylamide gel electrophoresis. The gel was then transferred on to a PVDF membrane (Millipore). The membranes were incubated with the blocking buffer containing $5 \%$ nonfat dry milk powder or bovine serum albumin for $2 \mathrm{~h}$ to reduce nonspecific binding sites and then incubated in mouse anti-GDNF, BDNF (1:200, Santa Cruz Biotechnology, USA), TH (1:1,500, Santa Cruz Biotechnology, USA), DAT(1:500), and VMAT2 $(1: 1,000)$ with gentle shaking overnight at $4{ }^{\circ} \mathrm{C}$. After this, membranes were incubated with their corresponding secondary antibodies (anti-rabbit or anti-mouse IgG conjugated to horseradish peroxidase) for $2 \mathrm{~h}$ at room temperature. The membrane was washed thrice with Tris-buffered saline and $0.05 \%$ Tween-20 for $30 \mathrm{~min}$. Protein bands were visualized by an enhanced chemiluminescence method using ECL kit (GenScript ECL kit, USA). Densitometric analysis was performed with a computer using a gel image analysis program. 


\section{Statistical Analysis}

All the data were expressed as mean $\pm \mathrm{SD}$ of number of experiments $(n=6)$. Statistical significance was evaluated by one-way analysis of variance using SPSS version 15.0 software, and individual comparisons were obtained using Duncan's multiple range test. Values were considered statistically significant if $P<0.05$.

\section{Result}

\section{Behavioral Studies}

\section{Effect of GE on Behavioral Recovery}

The results of spontaneous motor activity performance by behavioral tests were shown in Figs. 1, 2, and 3, respectively. Compared with control mice, the MPTP-treated mice displayed a significant decrease in spontaneous motor activity by latency to fall of the rotarod test, reduce forepaw stride distance, and decreased the number of steps in footprint test $(P<0.05)$. However, GE pretreatment significantly ameliorated these behavioral deficits induced by MPTP toxicity $(P<0.05)$

\section{Biochemical Studies}

Effects of GE on the Levels of MDA and GSH in the ST

To understand the mechanisms of the protective effects of GE, we measured the activities of GSH and the MDA contents in the ST of every group of mice. The results of these biochem-

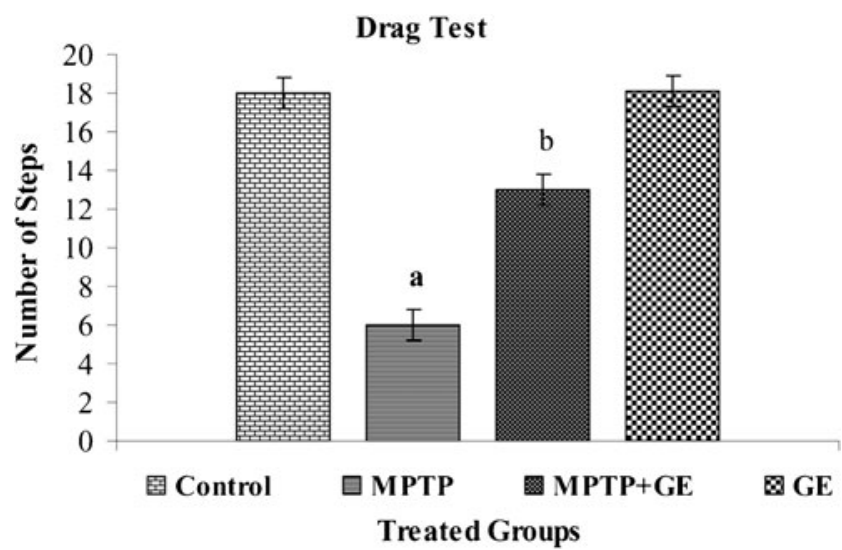

Fig. 2 Drag test performance after the acute regimen of GE and MPTP: Pretreated with GE to MPTP group a profound improvement in sensory motor performance. Values are given as mean $\pm \mathrm{SD}$ for six mice in each group. a $P<0.05$ compared to the control, b $P<0.05$ compared to the MPTP control

ical parameters were shown in Table 1. The contents of MDA in the ST of MPTP-treated mice were significantly increased compared with those in the control group $(P<0.05)$. However, the increase in MDA level was significantly ameliorated when the mice received GE pretreatment $(P<0.05)$. In addition, the GSH activity in MPTP-treated mice was significantly decreased compared with control group $(P<0.05)$, and GE pretreatment largely attenuated the decrease in GSH $(P<0.05)$.

Effects of GE on the Levels of Dopamine and Its Metabolites in the Striatum

The results of catecholamine measurement were shown in Table 2. The present study confirmed that catecholamine levels
Fig. 1 Rotarod performance after the acute regimen of GE and MPTP: pretreatment with GE improved MPTP-induced motor deficits. Mice were tested for motor function using the rotarod (motor function) test in different $\operatorname{rpm}(5,10,15$, and $20 \mathrm{rpm})$. Values are given as mean $\pm \mathrm{SD}$ for six mice in each group. a $P<0.05$ compared to the control, b $P<0.05$ compared to the MPTP control

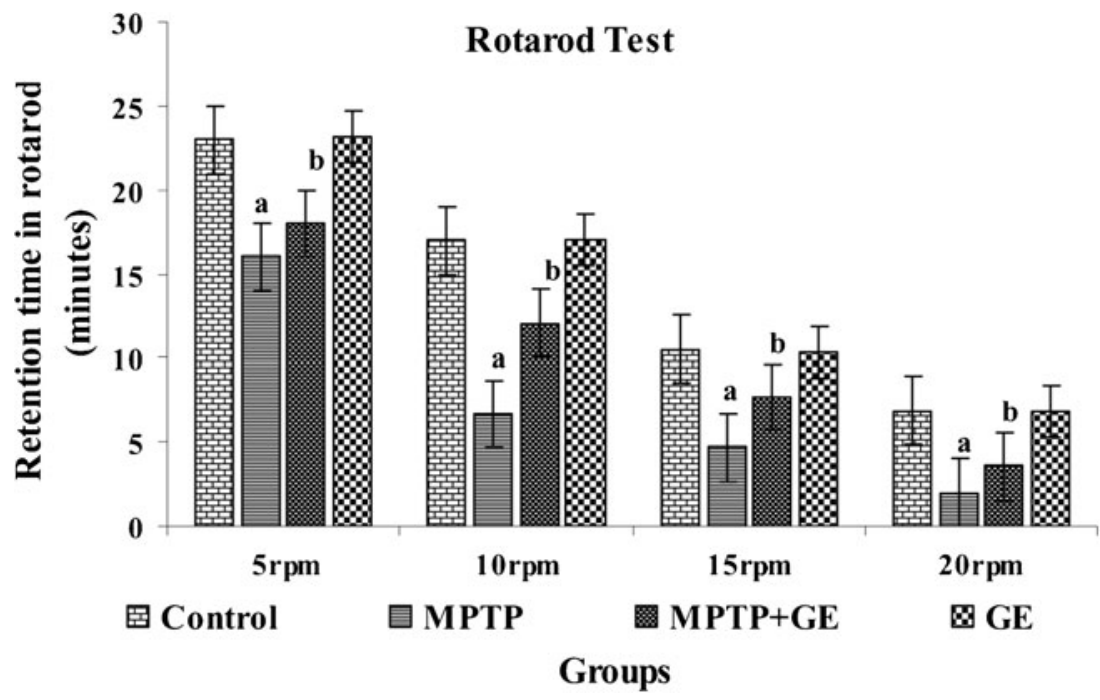




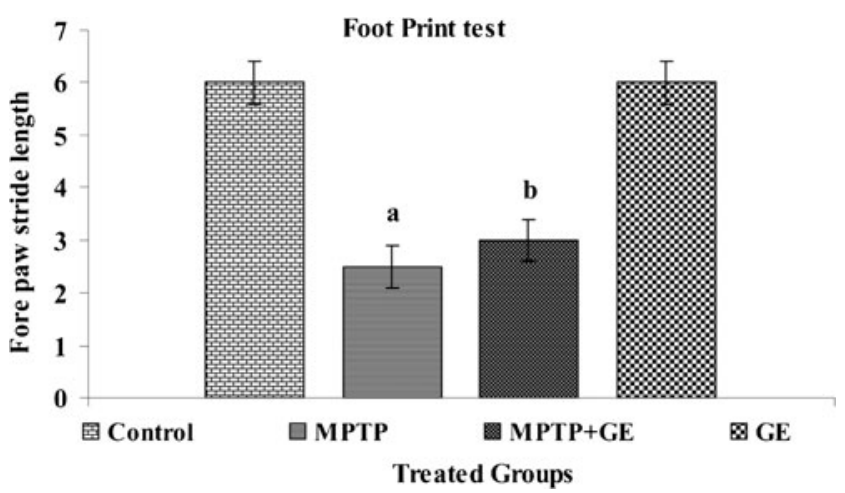

Fig. 3 Comparison of behavioral output between control and MPTPtreated mice. The footprint patterns were calculated from the stride length, mid digit toe of the first step, to the heel of the second step. The GE pretreatment improves the stride length after MPTP treatment. Values are given as mean $\pm \mathrm{SD}$ for six mice in each group. a $P<0.05$ compared to the control, $\mathbf{b} P<0.05$ compared to the MPTP control

were significantly decreased in MPTP-treated mice as compared to control mice. Pretreatment with GE following MPTP exposure significantly attenuated the decrease in the levels of DA, DOPAC, and HVA $(P<0.05)$. However, treatment with GE alone in MPTP-treated mice did not change the levels of DA and its metabolites as compared to control mice.

Effect of GE on MPTP-Induced Reduction of TH Immunoreactivity in the SN

Representative microphotographs of TH immunostaining in the SN were shown in Fig. 4a, b. Animals that received the treatment of MPTP injection showed a marked loss of THimmunopositive neurons in the SN compared with the control group. In contrast, GE-treated mice showed significantly reduced nigrostriatal dopaminergic neuron loss following MPTP injection at the dose of $30 \mathrm{mg} / \mathrm{kg}$ as compared to MPTP alone treated group $(P<0.05)$.

Table 1 The effects of GE on the levels of MDA and GSH in the striatum

\begin{tabular}{lll}
\hline Groups/variables & $\begin{array}{l}\text { MDA } \\
\text { (nmol/mg protein) }\end{array}$ & GSH (mg/g of tissue) \\
\hline Control & $1.3533 \pm 0.04$ & $23.423 \pm 0.17$ \\
MPTP & $0.7683 \pm 0.03^{\mathrm{a}}$ & $16.613 \pm 0.16^{\mathrm{a}}$ \\
MPTP + GE & $0.9217 \pm 0.04^{\mathrm{b}}$ & $19.411 \pm 0.17^{\mathrm{b}}$ \\
GE & $1.2850 \pm 0.09$ & $23.500 \pm 0.13$ \\
\hline
\end{tabular}

Mice were sacrificed after the last behavioral assessment, and the striatum was dissected for biochemical evaluation. All values are expressed as mean $\pm \mathrm{SD}$

${ }^{\text {a }} P<0.05$ compared with control group

${ }^{\mathrm{b}} P<0.05$ compared with MPTP treatment group
Table 2 The effects of GE on the levels of catecholamine in the striatum

\begin{tabular}{llll}
\hline $\begin{array}{l}\text { Groups/ } \\
\text { variables }\end{array}$ & $\begin{array}{l}\text { DA } \\
\text { (ng/mg tissue) }\end{array}$ & $\begin{array}{l}\text { DOPAC } \\
\text { (ng/mg tissue) }\end{array}$ & $\begin{array}{l}\text { HVA } \\
\text { (ng/mg tissue) }\end{array}$ \\
\hline Control & $13.7917 \pm 1.04836$ & $2.0900 \pm .16125$ & $1.3000 \pm .09879$ \\
MPTP & $3.1900 \pm .24633^{\mathrm{a}}$ & $0.9867 \pm .06976^{\mathrm{a}}$ & $0.4200 \pm .03162^{\mathrm{a}}$ \\
MPTP + GE & $10.2917 \pm .78418^{\mathrm{b}}$ & $1.3500 \pm .10296^{\mathrm{b}}$ & $0.7000 \pm .05367^{\mathrm{b}}$ \\
GE & $13.8017 \pm 1.04836$ & $1.9967 \pm .11075$ & $1.3100 \pm .09879$ \\
\hline
\end{tabular}

Mice were sacrificed after the last behavioral assessment, and the striatum was dissected for dopamine and its metabolites (DOPAC and $H V A$ ) evaluation. All values are expressed as mean $\pm \mathrm{SD}$

${ }^{\text {a }} P<0.05$ compared with control group

${ }^{\mathrm{b}} P<0.05$ compared with MPTP treatment group

The Expression of BDNF and GDNF in the MPTP Lessoned ST

The mRNA and proteins expressions of BDNF and GDNF revealed that the MPTP treatment significantly decreased mRNA (Fig. 5a, b) and protein expression level (Fig. 6a, b) of BDNF and GDNF as compared to control group, but GE pretreatment retained both expression and production of BDNF and GDNF activity as compared to the MPTP-treated group of mice $(P<0.05)$. No significant changes were observed between control and GE alone treated mice.

The Effect of GE on MPTP-Induced TH, DAT, and VMAT2 Level in ST

As shown in Fig. 7a, b, MPTP treatment significantly decreased the protein expression of TH, DAT, and VMAT2 in ST as compared to control group $(P<0.05)$. GE pretreatment restored TH, DAT, and VMAT2 protein generation as compared to the MPTP-treated group of animal $(P<0.05)$. No significant changes were observed between control and GE alone treated mice.

\section{Discussion}

In this study, we demonstrated that GE, which is capable of traversing the cellular membrane and can suppress $\mathrm{MPP}^{+}$ (toxic metabolite from MPTP)-induced lipid peroxidation and mRNA expressions and protect dopaminergic neurons in the ST of the brain from MPTP insult through upregulating NTFs and dopaminergic transporters in mice. As a novel astrocyte modulating agent, GE has a potent neuroprotective affect in mice model PD providing evidence that astrocytes can be a new target of neuroprotection. Intraperitoneal administration of neurotoxin MPTP induces more obvious loss of dopaminergic neurons in the ST and SN in C57BL/6 mice (Filipov et al. 2009; Yasuda et al. 2008). 
$4 X$
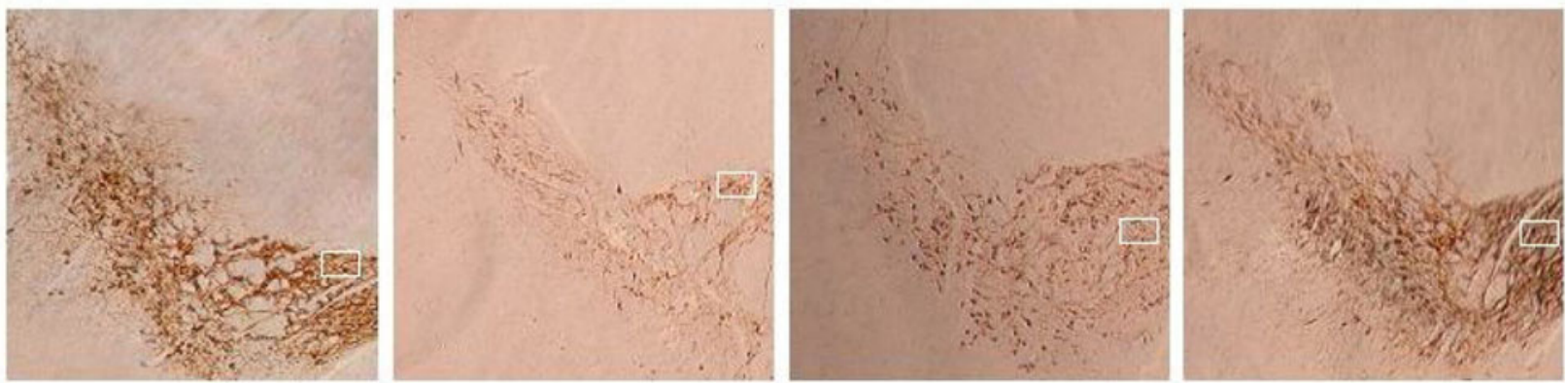

40X
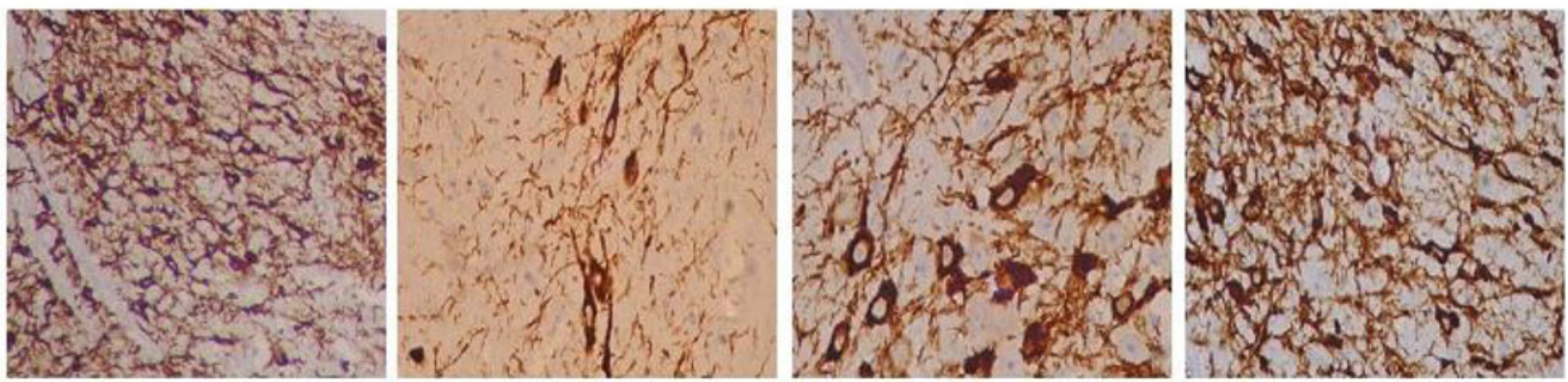

b

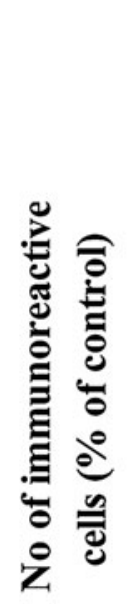

TH immunoreactivity in SN

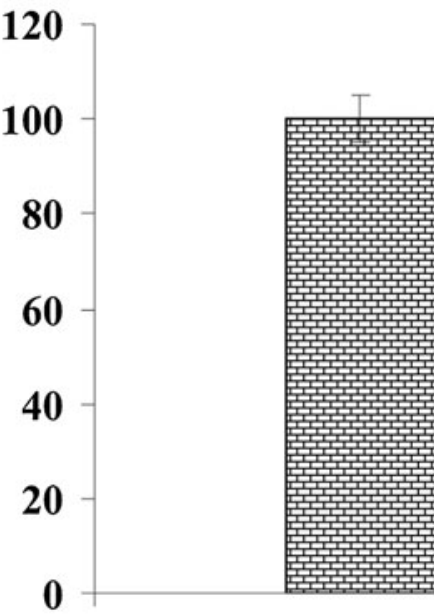

園 Control

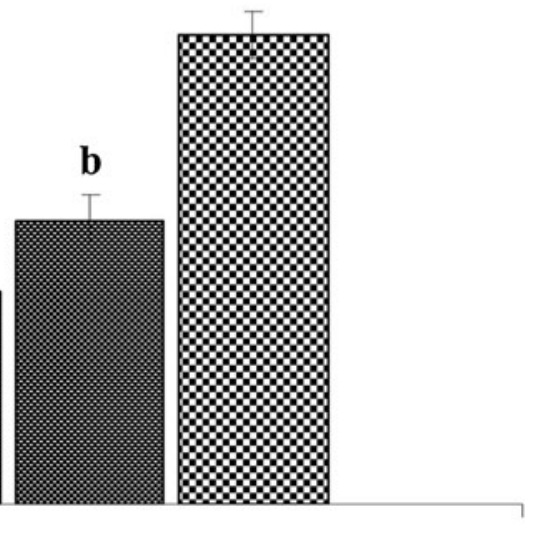

MPTP+GE $\quad$ G GE

\section{Groups}

Fig. 4 a Effect of GE on TH expression in SN. Representative microphotographs of the expression of TH was almost negligible in MPTP group as compared to control group, while the MPTP group treated with GE has shown a moderate staining of TH. However, the GE control group has shown no discernible change in TH staining as compared to control group. Original magnifications at $\times 4$ and $\times 40$. $b$ Quantification

Our experiments on the behavioral study suggesting that MPTP-induced DA depletion relate specifically to the diminished muscular coordination and balance (Moon et al. 2009) rather than an influence on the motor capacity of mice. of TH-IR was performed by counting the number of TH-IR neurons in $\mathrm{SN}$. The mean value for TH-IR was determined for each group and was expressed as a percentage of that matched control mice. Values are expressed as mean \pm SD of three mice per group. a $P<0.05$, compared with the control. b $P<0.05$, compared with the MPTP control group

The behavioral effects are intertwined with the degree of dopaminergic neuronal dysfunction (Schwarting et al. 1991); its assessment is a more powerful endpoint in evaluating neuroprotection against degeneration. Therefore, testing the 
a BDNF (205bp)
A B
C
D

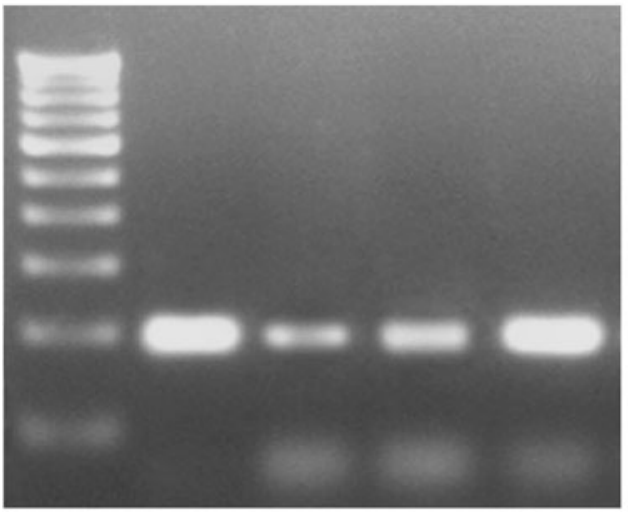

$\beta$-actin
A B
C
D

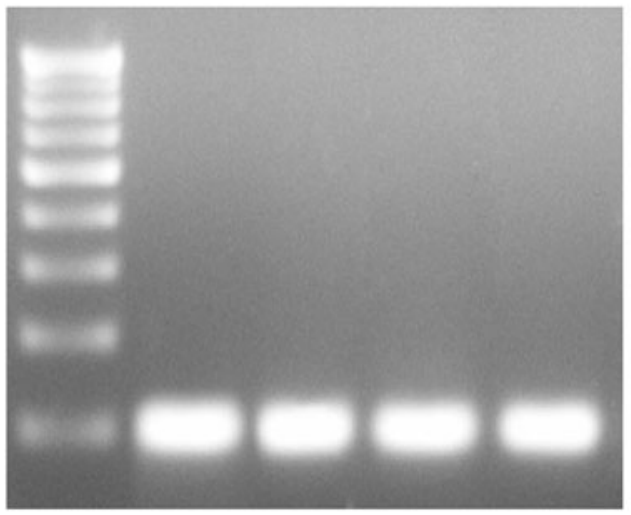

\section{GDNF (222bp)}
$\begin{array}{llll}A & B & C & D\end{array}$

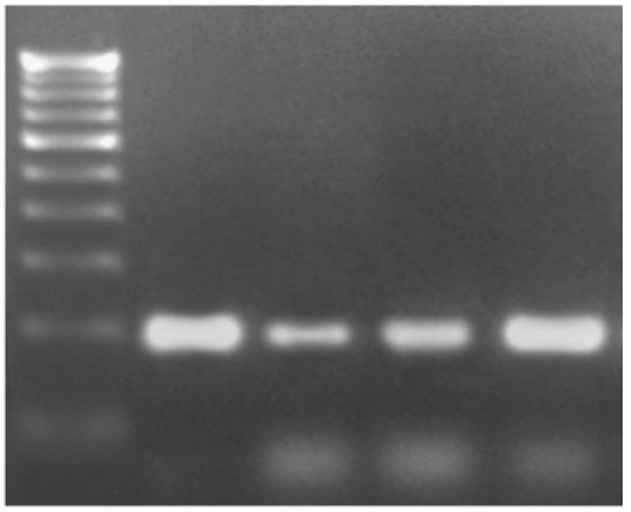

GAPDH

A $\quad$ B $\quad$ C $\quad$ D

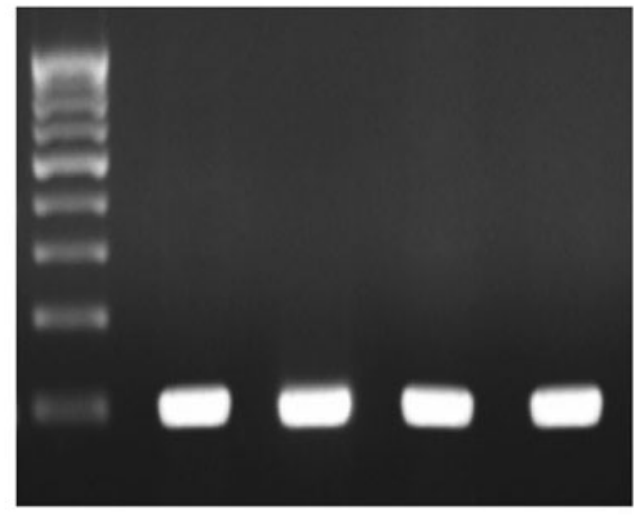

b BDNF and GDNF mRNA expression in ST

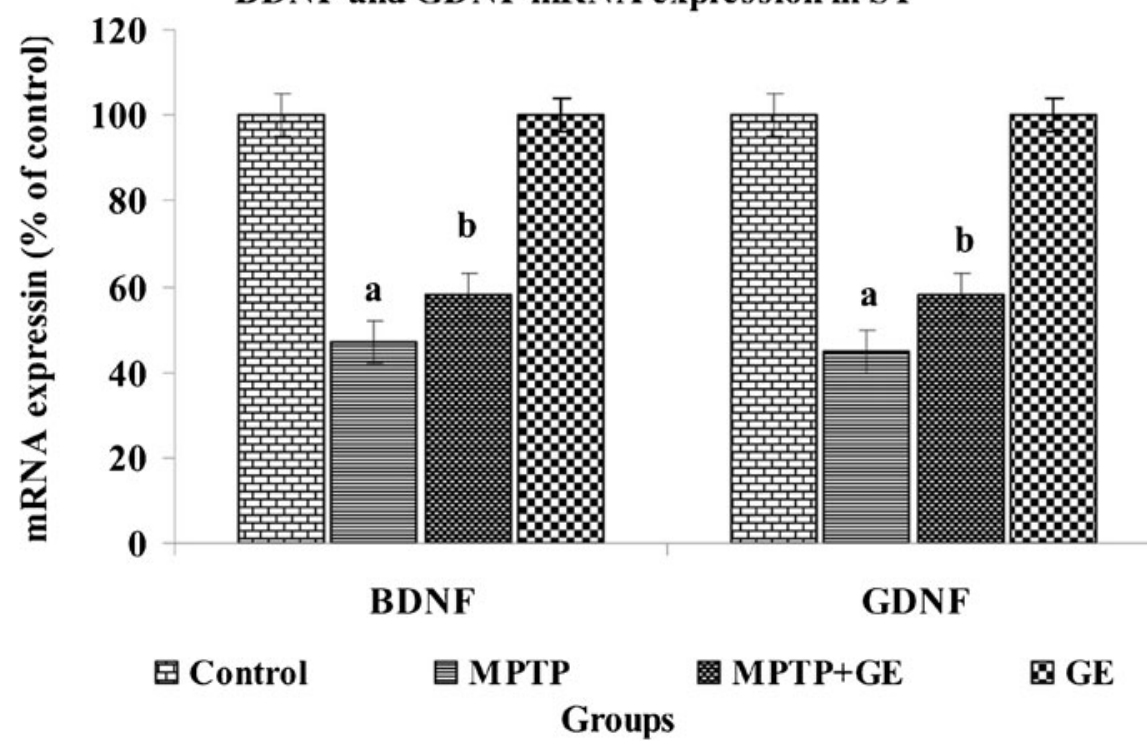

Fig. 5 a BDNF and GDNF mRNA expression level changes in ST of control and experimental mice, and $\beta$-actin and GAPDH mRNA were used as housekeeping gene for the normalization of mRNA expressions. b Quantification graphs values are expressed as mean \pm SD of three mice per group. a $P<0.05$, compared with the control. b $P<0.05$, compared with the MPTP control group 
Fig. 6 a Western blot analysis of BDNF and GDNF expression levels in ST. Western blot was performed to study the protein expression levels of BDNF and GDNF in the striatal tissue after GE treated and GE non-treated mice. b Bar graph shows the comparison among the group, and density was quantified by scanning densitometry. Values are expressed as mean $\pm \mathrm{SD}$ of three mice per group. a $P<0.05$, compared with the control. b $P<0.05$, compared with the MPTP control group a

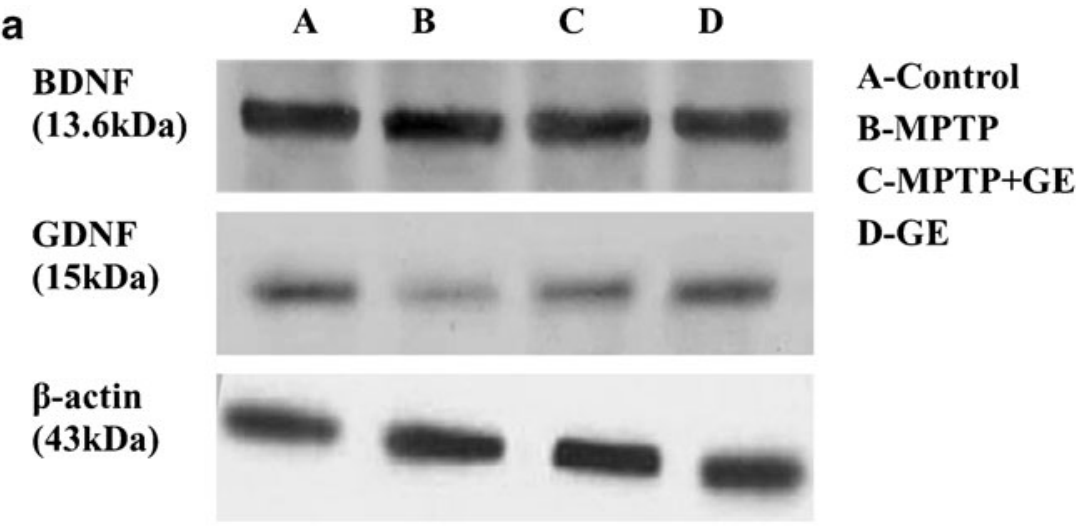

b

BDNF and GDNF Western Blot Densitometry in ST

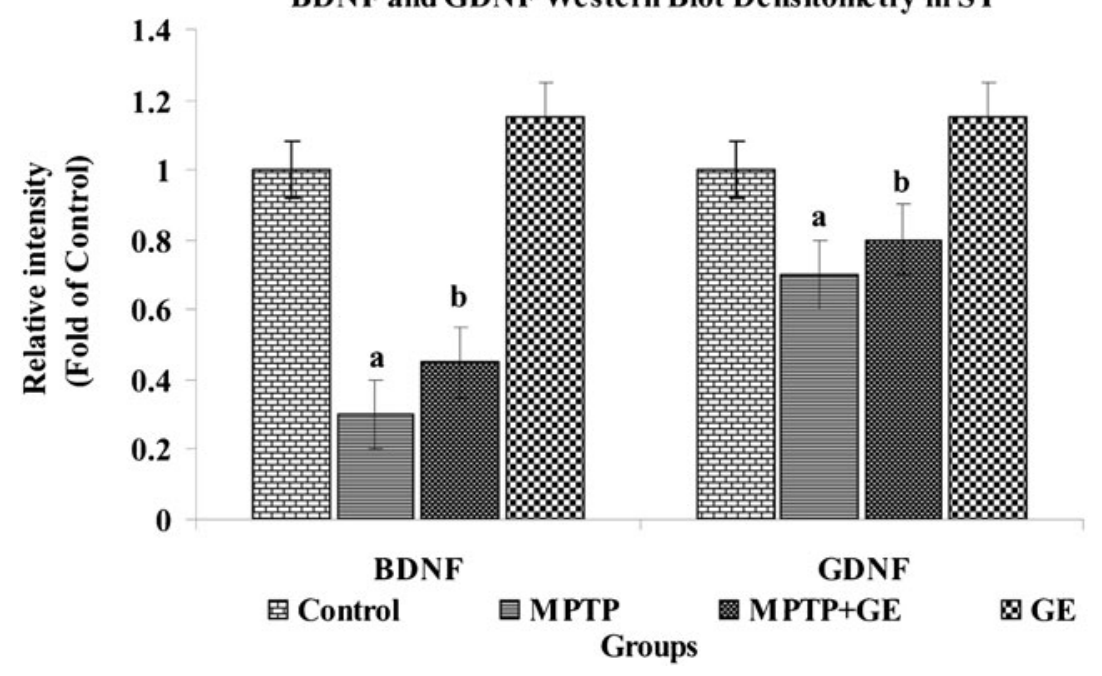

behavioral function in the current study provides a sensitive evaluation of new therapeutic agent without any undesirable effects. Our study results suggest that acute MPTP injections caused severe motor deficits as assessed by rotarod, foot print analysis, and drag test in mice after the last MPTP administration. Pretreatment with GE significantly alleviate these behavior deficits by improved motor coordination. Moreover, it was revealed that this effect of GE was closely associated with the protection of nigrostriatal dopaminergic neurons against MPTP-induced neurotoxicity in the brain. Pretreatment with GE was found to improve motor deficits by increase of striatal catecholamine levels after MPTP injection. These behavioral alterations were consistent with a previous report (Sundstrom et al. 1990).

While this study provides evidence against MPTP-induced LPO by evaluating MDA, it is a well-known mechanism of cellular injury initiated by ROS (Sayre et al. 2001). The cytotoxic aldehydes produced in the process of LPO and production could reflect the oxidative damage to lipids and proteins that leads to the pathological process of PD (Esterbauer et al. 1991; Alam et al. 1997). We revealed that pretreatment with GE evidently decreases the formation of MDA of MPTP- treated mice ST tissue. GSH is the most important thiolcontaining antioxidant in the brain (Meister and Anderson 1983), and it plays a pivotal role in preventing oxidative damage. It also has been used as a biomarker of oxidative stress in biological systems (Reed and Savage 1995). Depletion of GSH has been observed in the ST of PD patients and in the MPTP model (Ferraro et al. 1986). These results demonstrated that GE restore the MPTP-induced oxidative insults in striatal systems, and it confers potent protection of GE for the DA neurons by acting in both directions to restore the balance of oxidant accumulation and clearance.

Additionally, present findings are in agreement with the earlier reports that DA level and motor deficits in Parkinsonian mice have been attenuated by antioxidant supplementation (Chung et al. 2011; Khan et al. 2010; Moon et al. 2009). The degrees of DA depletion are established by the evaluation of TH levels, the rate limiting enzyme of DA biosynthesis, as an indirect indicator of DA, which could be markedly decreased by MPTP (Stephenson et al. 2007; Chen et al. 2009). The observed result showed that the administration of MPTP in ST could reach a modest but statistical significance to reduce the level of TH in ST. GE effectively reversed the reduced expression of $\mathrm{TH}$ and 
Fig. 7 a Western blot analysis of TH, DAT, and VMAT2 in ST of control and experimental mice. b The band density was quantified by scanning densitometry. Bar graph shows the comparison among groups. Values are expressed as mean $\pm \mathrm{SD}$ of three mice per group. a $P<0.05$, compared with the control. $\mathbf{b}$ $P<0.05$, compared with the MPTP control group a

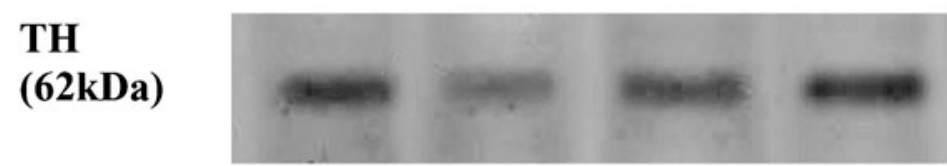

DAT (80kDa)

VMAT-2 (80 kDa)

$\beta$-actin (43 kDa)
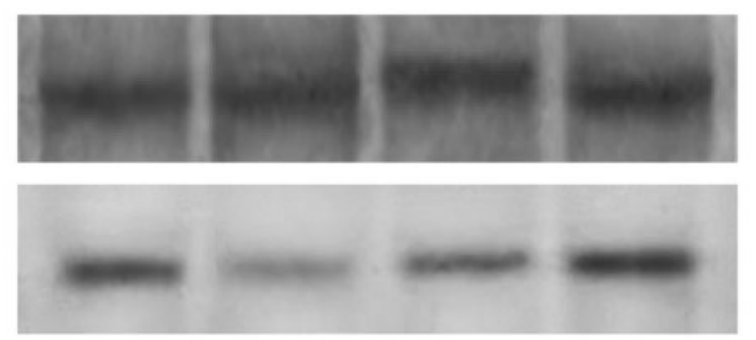

C-MPTP+GE

\section{D-GE}

b

\section{TH, DAT, VMAT-2 Western Blot Densitometry in ST}

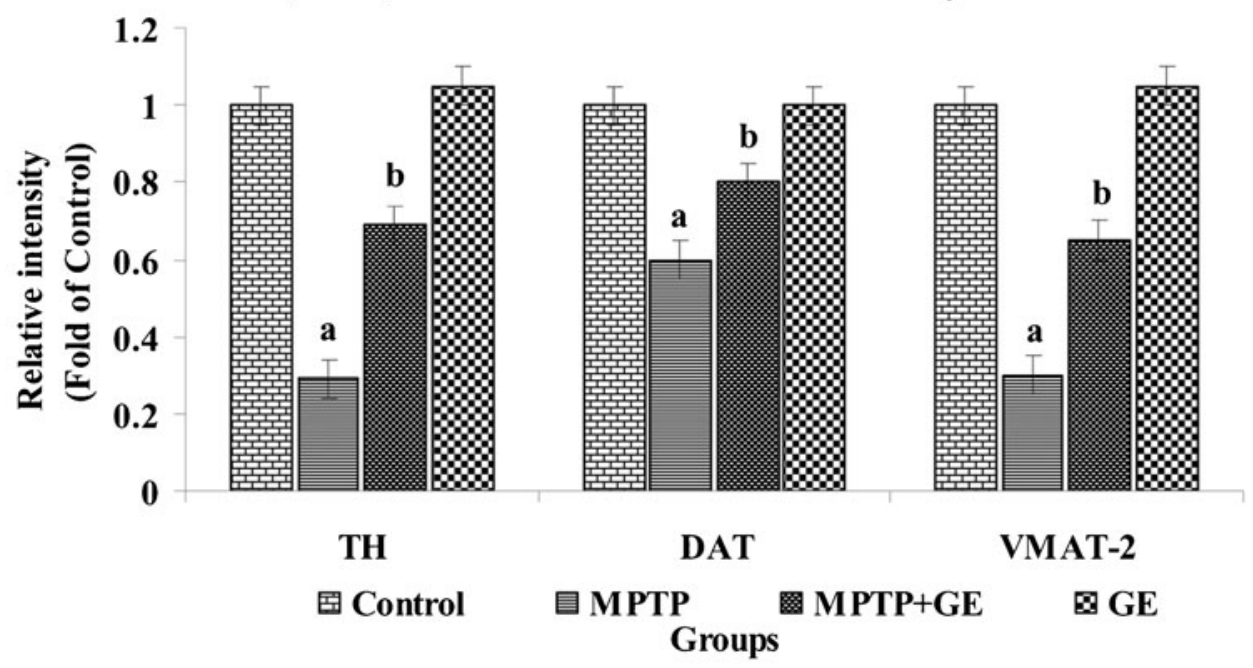

prevented gradual loss of neurons in SN and ST. DAT and VMAT2, two different transporters for DA and the dopaminergic toxins, had been regarded as injury index of dopaminergic neurons, which is helpful for early detection and intervention of PD. DAT is a critical regulator of DA distribution within the brain and is also a crucial determiner of the neurotoxicity of $\mathrm{MPP}^{+}$. DAT downregulation was probably a long-term compensatory mechanism directed at maintaining DA input in the ST (Afonso-Oramas et al. 2010) or preventing toxin to enter into neurons (Bezard et al. 2003). The study demonstrated that one component of the neuroprotection conferred by GE is to regulate the expression of DAT and VMAT2 in the MPTP-induced mice, which may influence the amount of neurotoxin uptake and the degree of lesion. Otherwise, the reduction of DAT may be correlated which influenced the transport of monoamine transmitter. The VMAT2 may serve as a neuroprotective factor by sequestering monoamines into vesicles and preventing the interaction with their catabolic enzymes (Caudle et al. 2008). In the present study, a decreased expression of DAT and VMAT2 were observed in the ST of MPTP-treated mice, which corresponds to the results of previous reports (Erickson et al. 1996; Weihe and Eiden 2000; Kurosaki et al. 2003).

The neuronal survival requires NTFs support. A limited availability of NTFs has been suggested to contribute to the mechanism of DA neurodegeneration in PD (Mogi et al. 1999), while they promote dopamine neurorescue in the mice and nonhuman MPTP models (Date et al. 1998; Lapchak et al. 1998; Wang et al. 2002). BDNF and GDNF are the most promising trophic factors in neurorescue or restorative treatment of neurodegenerative diseases, particularly in PD (Anand 2004; Bespalov and Saarma 2007). The development of therapeutic drug that modulate the functions of these factors, study from our laboratory established that a partial loss of GDNF and BDNF mice decline in motor function and the DA system 
(Boger et al. 2006, 2007). Furthermore, we found that pre intake of GE markedly counteracted neurotoxic effects of MPTP and restored the expression, activity, and generation of BDNF and GDNF, which benefited dopamine synthesis in brain. These findings implied that GE could prevent PD progression through regulating neurotrophic factors, stabilizing $\mathrm{TH}$, and protecting dopaminergic neurons, which consequently favored dopamine formation (Tsai et al. 2011).

\section{Conclusion}

In conclusion, the present study corroborated that the neuroprotective efficacy of GE in MPTP induced neurotoxicity. The protective effects were affirmed by improved motor coordination, expressions of NTFs, and inhibiting oxidative stress, increasing the counts of dopaminergic immunoreactive neurons. Based on the current result of our investigation, we speculate that GE might be a promising contender for the prevention or treatment of oxidative stress-related neurodegenerative disorders such as Parkinson's disease, but further studies are warranted to determine the possible role of GE in neurodegenerative process.

\section{Conflict of Interest No conflict of interest}

Open Access This article is distributed under the terms of the Creative Commons Attribution License which permits any use, distribution, and reproduction in any medium, provided the original author(s) and the source are credited.

\section{References}

Abercrombie M (1946) Estimation of nuclear population from microtome sections. Anat Rec 94:239-247

Afonso-Oramas D, Cruz-Muros I, Barroso-Chinea P, Alvarez de la Rosa D, CastroHernandez J, Salas-Hernandez J, Giraldez T, GonzalezHernandez T (2010) The dopamine transporter is differentially regulated after dopaminergic lesion. Neurobiol Dis 40:518-530

Alam ZI, Daniel SE, Lees AJ, Marsden DC (1997) A generalized increase in protein carbonyls in the brain in Parkinson's but not incidental Lewy body disease. J Neurochem 69:1326-1329

Anand P (2004) Neurotrophic factors and their receptors in human sensory neuropathies. Prog Brain Res 146:477-492

Bespalov MM, Saarma M (2007) GDNF family receptor complexes are emerging drug targets. Trends Pharmacol Sci 28:68-74

Bezard E, Dovero S, Belin D (2003) Enriched environment confers resistance to 1-methyl-4-phenyl-1, 2, 3, 6-tetrahydropyridine and cocaine: involvement of dopamine transporter and trophic factors. J Neurosci 23:10999-11007

Boger HA, Middaugh LD, Huang P, Zaman V, Smith AC, Hoffer BJ, Tomac AC (2006) A partial GDNF depletion leads to earlier age related deterioration of motor function and tyrosine hydroxylase expression in the substantia nigra. Exp Neurol 202:336-347

Boger HA, Middaugh LD, Patrick KS (2007) Long-term consequences of methamphetamine exposure in young adults are exacerbated in glial cell line-derived neurotrophic factor heterozygous mice. J Neurosci 27:8816-8825

Caudle WM, Colebrooke RE, Emson PC, Mille GW (2008) Altered vesicular dopamine storage in Parkinson's disease: a premature demise. Trends Neurosci 31:303-308

Chen PC, Vargas MR, Pani AK, Smeyne RJ, Johnson DA, Kan YW (2009) Nrf2 mediated neuroprotection in the MPTP mouse model of Parkinson's disease: critical role for the astrocyte. Proc Natl Acad Sci 106:2933-2938

Chung YC, Kim SR, Park JY, Chung ES, Park KW, Won SY, Bok E, Jin M, Park ES, Yoon SH, Ko HW, Kim YS, Jin BK (2011) Fluoxetine prevents MPTP-induced loss of dopaminergic neurons by inhibiting microglial activation. Neuropharmacology 60:963-974

Collier TJ, Kanaan NM, Kordower JH (2011) Aging as a primary risk factor for Parkinson's disease: evidence from studies of nonhuman primates. Nat Rev Neurosci 12:359-366

Date I, Aoi M, Tomita S, Collins F, Ohmoto T (1998) GDNF administration induces recovery of the nigrostriatal dopaminergic system both in young and aged Parkinsonian mice. NeuroReport 9:2365-2369

Dowd E, Monville C, Torres EM, Wong LF, Azzouz M, Mazarakis ND, Dunnett SB (2005) Lentivector mediated delivery of GDNF protects complex motor functions relevant to human Parkinsonism in a rat lesion model. Eur J Neurosci 22:2587-2595

Eberhardt O, Schulz JB (2003) Apoptotic mechanisms and antiapoptotic therapy in the MPTP model of Parkinson's disease. Toxicol Lett 139:135-151

Erickson JD, Schafer MK, Bonner TI, Eiden LE, Weihe E (1996) Distinct pharmacological properties and distribution in neurons and endocrine cells of two isoforms of the human vesicular monoamine transporter. Proc Natl Acad Sci 93:5166-5171

Escames G, Guerrero JM, Reiter RJ, Garcia JJ, MunozHoyos A, Ortiz GG (1997) Melatonin and vitamin E limit nitric oxide induced lipid peroxidation in rat brain homogenates. Neurosci Lett 230:147-150

Esterbauer H, Schaur RJ, Zollner H (1991) Chemistry and biochemistry of 4-hydroxynonenal, malonaldehyde, and related aldehydes. Free Radic Biol Med 11:81-128

Ferraro TN, Golden GT, DeMattei M, Hare TA, Fariello RG (1986) Effect of 1-methyl-4-phenyl-1,2,3,6-tetrahydropyridine (MPTP) on levels of glutathione in the extrapyramidal system of the mouse. Neuropharmacology 25:1071-1074

Filipov NM, Norwood AB, Sistrunk SC (2009) Strain-specific sensitivity to MPTP of C57BL/6 and BALB/c mice is age dependent. Neuroreport 20:713-717

Hartmann A, Troadec J, Hunot S, Kikly K, Baptiste A (2001) Caspase-8 Is an effector in apoptotic death of dopaminergic neurons in Parkinson's disease, but pathway inhibition results in neuronal necrosis. J Neurosci 21:2247-2255

Hirsch EC (2007) Animal models in neurodegenerative diseases. J Neural TransmSuppl 87-90

Hong M, Mukhida K, Mendez I (2008) GDNF therapy for Parkinson's disease. Expert Rev Neurother 8:1125-1139

Jenner P, Olanow CW (1998) Understanding cell death in Parkinson's disease. Ann Neurol 44:72-84

Jollow D, Mitchell L, Zampaglione N, Gillete J (1974) Bromobenzene induced liver necrosis: protective role of glutathione and evidence for 3, 4-bromobenzenoxide as the hepatotoxic intermediate. Pharmacology 11:151-169

Khan MM, Hoda MN, Ishrat T, Ahmad A, Khan MB, Khuwaja G, Raza SS, Safhi MM, Islam F (2010) Amelioration of 1-methyl-4-phenyl1,2,3,6-tetrahydropyridine induced behavioral dysfunction and oxidative stress by Pycnogenol in mouse model of Parkinson's disease. Behav Pharmacol 21:563-571

Kingston PA, Zufall F, Barnstable CJ (1996) Rat hippocampal neurons express genes for both rod retinal and olfactory cyclic nucleotide gated channels: novel targets for cAMP/cGMP function. Proc Natl Acad Sci 93:10440-10445 
Kordower JH, Emborg ME, Bloch J, Ma SY, Chu Y, Leventhal L, McBride J, Chen EY, Palfi S (2000) Neurodegeneration prevented by lentiviral vector delivery of GDNF in primate models of Parkinson's disease. Science 290:767-773

Kurosaki R, Muramatsu Y, Watanabe H, Michimata M, Matsubara M, Imai Y, Araki T (2003) Role of dopamine transporter against MPTP (1-methyl-4-phenyl-1,2,3,6-tetrahydropyridine) neurotoxicity in mice. Metab Brain Dis 18:139-146

Lapchak PA, Araujo DM, Hilt DC, Jiao S, Collin F, Miyoshi Y, Yi A, Zhang Z, Gash DM (1998) Topographical distribution of [125I]glial cell line derived neurotrophic factor in unlesioned and MPTPlesioned rhesus monkey brain following a bolus intraventricular injection. Brain Res 789:9-22

Lau YS, Novikova L, Roels C (2005) MPTP treatment in mice does not transmit and cause Parkinsonian neurotoxicity in non-treated cagemates through close contact. Neurosci Res 52:371-378

Lin AM, Yang CH, Ueng YF, Luh TY, Liu TY, Lay YP, Ho LT (2004) Differential effects of carboxyfullerene on MPP+/MPTP-induced neurotoxicity. Neurochem Int 44:99-105

Lin LF, Doherty DH, Lile JD, Bektesh S, Collins F (1993) GDNF: a glial cell line derived neurotrophic factor for midbrain. Science 260:1130-1132

Lindsay RM, Wiegand SJ, Altar CA, DiStefano PS (1994) Neurotrophic factors: from molecule to man. Trends Neurosci 17:182-190

Lowry OH, Rosebrough NJ, Farr AL, Randall RJ (1951) Protein measurement with the Folin phenol reagent. J Biol Chem 193:265-275

Madankumar A, Jayakumar S, Gokuladhas K, Rajan B, Raghunandhakumar S, Asokkumar S, Devaki T (2013) Geraniol modulates tongue and hepatic phase I and phase II conjugation activities and may contribute directly to the chemopreventive activity against experimental oral carcinogenesis. Eur J Pharmacol 705:148-155

Meister A, Anderson ME (1983) Glutathione. Annu Rev Biochem 52:711-760

Mogi M, Togari A, Kondo T, Mizuno Y, Komure O, Kuno S, Ichinose H, Nagatsu T (1999) Brain-derived growth factor and nerve growth factor concentrations are decreased in the substantia nigra in Parkinson's disease. Neurosci Lett 270:45-48

Moon M, Kim HG, Hwang L, Seo JH, Kim S, Hwang S, Kim S, Lee D, Chung H, Oh MS, Lee KT, Park S (2009) Neuroprotective effect of ghrelin in the 1-methyl-4-phenyl-1,2,3,6-tetrahydropyridine mouse model of Parkinson's disease by blocking microglial activation. Neurotox Res 15:332-347

Muralikrishnan D, Mohanakumar KP (1998) Neuroprotection by bromocriptine against 1-methyl-4-phenyl-1,2,3,6-tetrahydropyridineinduced neurotoxicity in mice. FASEB J 12:905-912

Nicholas AP (2007) Levodopa induced hyperactivity in mice treated with 1-methyl-4-phenyl-1, 2, 3, 6-tetrahydropyridine. Mov Disord 22:99-104

Peterson AL, Nutt JG (2008) Treatment of Parkinson's disease with trophic factors. Neurotherapeutics 5:270-280

Przedborski S, Tieu K, Perier C, Vila M (2004) MPTP as a mitochondrial neurotoxic model of Parkinson's disease. J Bioenerg Biomembr 36:375-379

Reed DJ, Savage MK (1995) Influence of metabolic inhibitors on mitochondrial permeability transition and glutathione status. Biochim Biophys Acta 1271:43-50

Rozas G, Lopez-Martin E, Guerra MJ, Labandeira-Garcia JL (1998) The overall rod performance test in the MPTP-treated mouse model of Parkinsonism. J Neurosci Methods 83:165-175

Saarma M (2000) GDNF - a stranger in the TGF-beta superfamily? Eur J Biochem 267:6968-6971

Sayre LM, Smith MA, Perry G (2001) Chemistry and biochemistry of oxidative stress in neurodegenerative disease. Curr Med Chem 8:721-738

Schober A (2004) Classic toxin-induced animal models of Parkinson's disease: 6-OHDA and MPTP. Cell Tissue Res 318:215-224
Schwarting RK, Bonatz AE, Carey RJ, Huston JP (1991) Relationships between indices of behavioral asymmetries and neurochemical changes following mesencephalic 6-hydroxydopamine injections. Brain Res 554:46-55

Schwarting RK, Huston JP (1996) The unilateral 6-hydroxydopamine lesion model in behavioral brain research. Analysis of functional deficits, recovery, and treatments. Prog Neurobiol 50:275-331

Smeyne RJ, Jackson-Lewis V (2005) The MPTP model of Parkinson's disease. Brain Res Mol Brain Res 134:57-66

Stephenson DT, Childs MA, Li Q, Carvajal-Gonzalez S, Opsahl A (2007) Differential loss of presynaptic dopaminergic markers in Parkinsonian monkeys. Cell Transplant 16:229-244

Sundstrom E, Fredriksson A, Archer T (1990) Chronic neurochemical and behavioral changes in MPTP-lesioned C57BL/6 mice: a model for Parkinson's disease. Brain Res 528:181-188

ansey MG, McCoy MK, Frank-Cannon TC (2007) Neuroinflammatory mechanisms in Parkinson's disease: potential environmental triggers, pathways, and targets for early therapeutic intervention. Exp Neurol 208:1-25

Tillerson JL, Caudle WM, Reveron ME, Miller GW (2002) Detection of behavioral impairments correlated to neurochemical deficits in mice treated with moderate doses of 1-methyl-4-phenyl-1,2,3,6tetrahydropyridine. Exp Neurol 178:80-90

Tiwari M, Kakkar P (2009) Plant-derived antioxidants geraniol and camphene protect rat alveolar macrophages against t-BHPinduced oxidative stress. Toxicol In Vitro 23:295-301

Tsai S, Chao C, Yin M (2011) Preventive and therapeutic effects of caffeic acid against inflammatory injury in striatum of MPTPtreated mice. Eur J Pharmacol 670:441-447

Viaro R, Sanchez-Pernaute R, Marti M, Trapella C, Isacson O, Morari M (2008) Nociceptin/orphanin FQ receptor blockade attenuates MPTP-induced Parkinsonism. Neurobiol Dis 30:430-438

Wang L, Muramatsu S, Lu Y, Ikeguchi K, Fujimoto K, Okada T, Mizukami H, Hanazono Y, Kume A, Urano F, Ichinose H, Nagatsu T, Nakano I, Ozawa K (2002) Delayed delivery of AAV-GDNF prevents nigral neurodegeneration and promotes functional recovery in a rat model of Parkinson's disease. Gene Ther 9:381-389

Weihe E, Eiden LE (2000) Chemical neuroanatomy of the vesicular amine transporters. FASEB J 14:2435-2449

Wright AM, Bempong J, Kirby ML, Barlow RL, Bloomquist JR (1998) Effects of haloperidol metabolites on neurotransmitter uptake and release: possible role in neurotoxicity and tardive dyskinesia. Brain Res 788:215-222

Wu DC, Jackson-Lewis V, Vila M, Tieu K, Teismann P, Vadseth C, Choi DK, Ischiropoulos H, Przedborski S (2002) Blockade of microglial activation is neuroprotective in the1-methyl-4-phenyl1,2,3,6-tetrahydropyridine mouse model of Parkinson's Disease. J Neurosci 22:1763-1771

Wu SS, Frucht SJ (2005) Treatment of Parkinson's disease - what's on the horizon? CNS Drugs 19:723-743

Xu G, Xiongy Z, Yong Y, Wang Z, Ke Z, Xia Z, Hu Y (2010) Catalpol attenuates MPTP-induced neuronal degeneration of niagral striatal dopaminergic pathway in mice through elevating glial cell derived neurotropic factor in striatum. Neuroscience 167:174-184

Yang X, Mertens B, Lehtonen E, Vercammen L, Bockstael O, Chtarto A, Levivier M, Brotchi J, Michotte Y, Baekelandt V, Sarre S, Tenenbaum L (2009) Reversible neurochemical changes mediated by delayed intrastriatal glial cell line derived neurotrophic factor gene delivery in a partial Parkinson's disease rat model. J Gene Med 11:899-912

Yasuda Y, Shimoda T, Uno K, Tateishi N, Furuya S, Yagi K (2008) The effects of MPTP on the activation of microglia/astrocytes and cytokine/ chemokine levels in different mice strains. J Neuroimmunol 204:43-51

Yurek DM, Fletcher-Turner A (2001) Differential expression of GDNF, BDNF, and NT-3 in the aging nigrostriatal system following a neurotoxic lesion. Brain Res 891:228-235 